\title{
As disciplinas pedagógicas na formação e na construção de representações sobre o trabalho docente: visões de alunos de licenciatura em Química e Física*
}

\section{Pedagogy subjects in the formation and in the construction of representations about teachers' work: views of preservice Chemistry and Physics teachers}

\author{
Pedro da Cunha Pinto Neto** \\ Salete Linhares Queiroz*** \\ Dulcimeire Ap. Volante Zanon****
}

\begin{abstract}
RESUMO
Este estudo tem como objetivo analisar as concepções de licenciandos em Química e em Física sobre a prática profissional e as marcas deixadas pelas disciplinas pedagógicas na sua formação, assim como identificar sinais de mudanças em suas concepções durante a realização do curso de Licenciatura. Para tanto, textos foram produzidos por 54 alunos matriculados em cursos de Licenciatura de duas universidades públicas do estado de São Paulo, nos quais os licenciandos expressaram suas experiências de formação e apontaram elementos que consideram que terão alguma influência em sua atuação profissional. Os textos revelaram que as ideias que os licenciandos carregam são consistentes com muitas das visões e objetivos apresentados em cursos de formação de professores. Nas produções dos estudantes faz-se presente o desejo de compartilhar e promover em seus

* Projeto desenvolvido com apoio do CNPq.

** Prof ${ }^{\circ}$. Dr ${ }^{\circ}$. do Departamento de Ensino e Práticas Culturais da FE/UNICAMP e pesquisador do Grupo de Estudos e Pesquisa em Ciência e Ensino - gepCE.

*** Prof ${ }^{\mathrm{a}}$. Dr ${ }^{\mathrm{a}}$. do Instituto de Química de São Carlos, Universidade de São Paulo e coordenadora do Grupo de Pesquisa em Ensino de Química do IQSC/USP.

**** Prof $^{\mathrm{a}}$. Dr ${ }^{\mathrm{a}}$. do Departamento de Didática da Faculdade de Ciências e Letras da UNESP de Araraquara e pesquisadora do Grupo de Pesquisa em Ensino de Química do IQSC/USP.
\end{abstract}


futuros alunos o interesse pela Química e a Física. Os seus comentários refletiram visões de professores que tiveram no passado, os quais gostariam de imitar, e de outros que não gostariam de ser. Os comentários também tornaram evidente a vontade dos licenciandos em se estabelecerem como professores que se preocupam com seus alunos. Os textos foram analisados segundo a Análise do Discurso de linha francesa, como tem sido divulgada por Eni Orlandi, especialmente a noção de formação discursiva.

Palavras-chave: formação de professores; licenciandos; Química; Física.

\begin{abstract}
The objective of this study is to analyze the views of preservice chemistry and physics teachers about the professional practice and the influence of pedagogic disciplines on their formation. Furthermore, it aims at identifying changes in preservice teachers' opinions and beliefs throughout their education. Hence, texts were produced by 54 undergraduate students who were undertaking preservice courses in two public universities in the state of São Paulo, in which they expressed their experiences throughout the course and mentioned relevant aspects about their professional development. The texts revealed that their ideas were consistent concerning many of the views and goals of teacher preparation courses. Their statements reflected desires to share and stimulate interest for chemistry and physics in their future students. Their comments evidenced past experiences they would like to emulate and others they would rather not. They also expressed their worries about becoming teachers who do care for their students. The texts were analyzed by Discourse Analysis, in its French approach, according to Eni Orlandi, especially the concept of discursive formation.

Keywords: teacher education; preservice teachers; chemistry; physics.
\end{abstract}

\title{
Introdução
}

A formação dos professores das Ciências (Física, Química, Biologia, Ciências Naturais e Matemática) tem sido sobremaneira discutida no meio acadêmico com desenvolvimento de diversas questões de pesquisas e enfoques teórico-metodológicos. Uma das vertentes, defendida por Tardif(2004), sustenta a ideia de que o trabalho docente está relacionado a uma variedade de saberes, tais como os saberes pessoais, os saberes provenientes da formação escolar 
anterior, os saberes da formação profissional, os saberes disciplinares, os saberes curriculares e os saberes experienciais. Por serem originários de diferentes fontes, os saberes docentes também incorporam as concepções de senso comum acerca do processo educativo construindo, por essa via, diversas crenças sobre o ensino, a aprendizagem, o papel da escola etc., as quais tendem a ser pouco afetadas pelos cursos de licenciatura.

Neste trabalho temos como objetivo analisar as concepções de estudantes matriculados no segundo e no quarto semestre da Licenciatura Integrada Química/Física da Universidade Estadual de Campinas (Unicamp) e no oitavo semestre da Licenciatura em Química da Universidade Paulista Júlio de Mesquita Filho (UNESP - Campus de Araraquara) sobre a prática profissional e as marcas deixadas pelas disciplinas específicas de formação de professores, assim como identificar sinais de possíveis mudanças em suas concepções durante o curso de Licenciatura.

Para tanto, solicitamos aos licenciandos a escrita de um texto, no qual expressassem suas experiências de formação no curso e apontassem os elementos que consideram que terão alguma influência em sua atuação profissional. Foi solicitado também que escrevessem como imaginam que será sua atuação profissional, e em que esta se diferenciará das suas experiências de formação no Ensino Médio.

A referida solicitação buscou provocar nos alunos uma reflexão sobre as possíveis articulações entre suas experiências no curso de formação e as projeções que fazem para o futuro e, ao mesmo tempo, olhando para o passado, isto é, para suas vivências enquanto estudantes no Ensino Médio. De certo modo buscamos identificar as rupturas e continuidades em relação a uma determinada experiência escolar, e até que ponto as disciplinas de formação contribuem nesse processo.

\section{Aportes teóricos}

Os aportes teóricos utilizados para analisar as interpretações dos licenciandos foram basicamente os textos da vertente da Análise de Discurso (AD) divulgada no Brasil por Eni P. Orlandi. Essa vertente considera a linguagem não apenas como um suporte do pensamento ou mero instrumento de comunicação, mas também como não transparente, ou seja, a relação entre linguagem, pensamento e mundo não é unívoca. Dessa forma, a linguagem passa a se caracterizar como transformadora, como interação, uma vez que ela reside na relação neces- 
sária entre homem e realidade natural e social (ORLANDI, 1993).

Podemos dizer, então, que as palavras produzem sentidos influenciados pelas condições de produção desse discurso que interferem na sua constituição e compreendem fundamentalmente os sujeitos e a situação, ou seja, o contexto histórico social de formulação do texto, os interlocutores (autor e a quem se dirige), os lugares (posições) em que eles (os interlocutores) se situam e em que são vistos, e as imagens que fazem de si próprios e dos outros, bem como o objeto da fala - o referente (ALMEIDA, 2004). Também a memória faz parte da produção do discurso e as circunstâncias da enunciação: o contexto imediato. Em sentido amplo, as condições de produção incluem o contexto sócio-histórico, ideológico sem nos esquecermos da história.

Os textos dos licenciandos podem ser vistos como uma produção inacabada, incompleta já que sempre são possíveis novas leituras e novos sentidos. Para Orlandi (2005) todo texto tem sua origem em outro texto e vai falar de outro texto no futuro. Daí a conclusão de que todo texto é, em essência, um mediador de um que já existiu e de outro que virá a ser e que "todo dizer, na realidade, se encontra na confluência dos dois eixos: o da memória (constituição) e o da atualidade (formulação). E é desse jogo que tiram seus sentidos" (ORLANDI, 2005, p. 33).

Para a análise das produções dos estudantes, tomamos como referência a noção de formações discursivas de Orlandi (1988, 1996, 2005) já que estamos trabalhando com alunos em diferentes momentos do curso de licenciatura, e considerando que estão trazendo para seus discursos elementos constitutivos das disciplinas pelas quais passaram.

A formação discursiva caracteriza-se como uma "matriz" do sentido: ela "dita as regras" para o que o sujeito pode e deve dizer no âmbito de suas práticas sociais e até mesmo para aquilo que não pode e não deve ser dito (ORLANDI, 2005). Essa concepção inicial de Pêcheux (1995) foi reformulada a partir das considerações de Foucault (1986) sobre a noção de formação discursiva que a considera como sendo um conjunto de enunciados que mantêm uma regularidade:

Isto é, conjunto de performances verbais que não estão ligadas entre si, ao nível das frases por laços gramaticais (sintáticos ou semânticos); que não estão ligados entre si, ao nível das proposições, por laços lógicos (de coerência formal ou encadeamentos conceituais); que tampouco estão ligados, ao nível das formulações, por laços psicológicos (que sejam a identidade das formas de consciência, a constância das mentalidades, ou a repetição de um projeto); mas que estão ligados ao nível dos enunciados (FOUCAULT, 1986, p. 144). 
Para compreender o que o sujeito diz (sente e acredita) é preciso relacionálo com outros dizeres que são exteriores a ele, mas que constituem o sentido de suas palavras e que correspondem a seus sentimentos e crenças. Dessa forma, a tarefa do analista do discurso é tentar reconstituir a partir dos enunciados dos sujeitos o jogo de relações (o que ele diz com a exterioridade), o que é bem diferente da pura observação de seu dizer e fazer. Isso implica dizer que, metodologicamente, não existem técnicas mais adequadas ou questionários mais bem elaborados, pois todos os enunciados são pertinentes. Tudo o que o sujeito dizer "mostrará", desde que saibamos "ler", suas relações com o processo ideológico do qual suas palavras fazem parte e a partir do qual se explicam.

\section{Coleta e análise dos dados}

Participaram da pesquisa trinta e três estudantes da Unicamp, dezenove do segundo semestre e quatorze do quarto. A escolha por esse grupo se deve, principalmente, ao fato do curso ter sofrido uma reformulação curricular a partir de 2006, sendo estas as primeiras turmas do novo currículo. Consideramos também o fato de que a proposta curricular da Licenciatura Integrada contempla disciplinas e atividades específicas da formação de professores logo no início do curso, sendo de nosso interesse olhar para os resultados dessa inserção. No novo currículo os alunos da Licenciatura Integrada Química/Física devem cursar um conjunto de cinco disciplinas voltadas especificamente para a formação de professores, e mais quatro atividades científico culturais, que no caso das turmas que participaram da pesquisa tiveram como foco questões relacionadas com a atuação do professor.

Cabe aqui destacar que a Licenciatura Integrada Química/Física é um curso específico de formação de professores, oferecido no período noturno, no qual os alunos optam pela Licenciatura em Física ou em Química ao concluírem a primeira metade do currículo, podendo depois retornar e concluir a outra modalidade. As disciplinas que chamamos de específicas para formação de professores são aquelas oferecidas pela Faculdade de Educação e por outras Unidades, voltadas diretamente para a formação do licenciado. Nesse caso, os estudantes que participaram da pesquisa ainda não tinham feito sua opção em relação à modalidade que cursariam, sendo que as disciplinas que cursaram até aquele momento fazem parte do núcleo comum.

Em relação ao curso de Licenciatura em Química, oferecido no período noturno da UNESP de Araraquara, participaram da pesquisa vinte e um alunos 
do oitavo semestre (quarto ano). Esses alunos fazem parte de uma estrutura curricular anterior a vigente que foi reformulada e implementada em 2006 tendo em vista as novas exigências da formação do profissional emitidas no Parecer CNE/CP 09/2001 e na Resolução CNE/CP 01/2002. Dessa forma, os alunos vivenciaram a antiga formação de professores em que as disciplinas pedagógicas estão concentradas no final do processo. Nesse contexto, as produções dos alunos foram coletadas no momento em que faltava apenas uma disciplina - a de Prática de Ensino e Estágio Supervisionado em Química, de 225 horas - para a conclusão do curso.

Em virtudes das distintas configurações dos cursos de formação inicial, mas também da teia de relações histórico-culturais, políticas, epistemológicas, pedagógicas e éticas inseridas nesses contextos interessou-nos analisar as marcas deixadas pelas disciplinas pedagógicas na formação e na construção de representações sobre o trabalho docente. Assim, as questões fornecidas aos licenciandos, na íntegra, foram:

Tomando como referência a situação descrita abaixo, escreva o seu texto. Você foi chamado para participar de um processo seletivo em uma escola que está contratando professores em formação para diversas áreas. É solicitado que escreva um texto abordando as seguintes questões.

1. Escreva sobre sua experiência de formação no curso de Licenciatura, especialmente das disciplinas relacionadas com sua atuação profissional, mostrando todos os elementos que considera que terão alguma influência na sua atuação profissional.

2. Caso venha a assumir o cargo de professor, como imagina que será sua atuação, e em que esta se diferenciará das suas experiências de formação no ensino médio?

A dificuldade na leitura dos enunciados dos estudantes reside na elaboração de mecanismos, de procedimentos que permitam interpretá-los e, nesse sentido, o dispositivo teórico-analítico da AD se define como um dispositivo de interpretação. Com esse dispositivo, fizemos um primeiro tratamento de análise superficial (processo de de-superficialização) observando o como se diz, a quem diz, em que circunstâncias etc., adquirindo pistas para a compreensão do modo como o discurso que pesquisamos se textualiza. Devemos considerar também que, como as palavras refletem sentidos de discursos, já realizados, imaginados ou possíveis, é desse modo que a história se faz presente na língua. Não vemos nos textos os "conteúdos" da história. Eles são tomados como discursos, em cuja materialidade está inscrita a relação com a exterioridade (ORLANDI, 
2005). Portanto, não estamos interessados no texto em si como objeto final de explicação, mas como unidade que nos permite ter acesso ao discurso. Como produtos de análise temos a compreensão dos processos de produção de sentidos e de constituição dos sujeitos em suas posições.

\section{Resultados e discussão}

A seguir apresentamos, separadamente, as análises dos textos dos licenciandos de cada um dos cursos para posteriormente tecermos considerações conjuntas sobre as marcas deixadas pelas disciplinas pedagógicas na formação e na construção de representações sobre o trabalho docente.

Discutimos as respostas dadas às questões buscando identificar subseções que pudessem facilitar tanto a compreensão dos licenciandos a respeito das mesmas como a organização da apresentação dos resultados; para tanto, trazemos as "vozes" dos licenciandos. Além disso, ressaltamos que as subseções não devem ser interpretadas isoladamente uma vez que elas se encontram imbricadas umas com as outras (NASCIMENTO; SOUSA, 2007).

\section{Textos de alunos do curso de Licenciatura Integrada Química/Fí- sica da UNICAMP}

Tomar como um dos focos da pesquisa a produção dos estudantes do segundo e do quarto semestre da Licenciatura Integrada Química/Física exige de nós um olhar atento para o contexto no qual o curso está inserido, assim como para o processo de reformulação pelo qual está passando. Este olhar nos permite uma aproximação com o lugar e as condições de produção dos textos que são nosso objeto de análise.

Primeiramente é importante destacar que a Licenciatura Integrada em Química/Física é um curso específico de formação de professores, oferecido no período noturno, numa parceria entre a Faculdade de Educação e os Institutos de Química e Física da Unicamp, sendo que a coordenação do curso está sediada na Faculdade de Educação. Desse modo, a relação acadêmica mais direta dos estudantes se dá com a Faculdade de Educação, local e ambiente no qual são inseridos ao ingressarem no curso e de onde falam ao escreverem sobre suas 
experiências de formação.

Uma das características da Licenciatura Integrada, desde a sua criação em 1999, é de oferecer, a partir do primeiro semestre, disciplinas que abordem questões relativas à atividade docente, rompendo com o modelo no qual a chamada "formação pedagógica" se dá apenas no final, como um complemento na formação dos bacharéis e tecnólogos. O currículo que passou a vigorar a partir de 2006 reforçou o modelo da formação ao longo do curso, incluindo nos quatro primeiros semestres as atividades científico-culturais, as quais receberam a denominação de Colóquios e Seminários, sendo oferecidas no formato de disciplinas, as quais estão sob a responsabilidade da coordenação do curso na Faculdade de Educação. Segundo o novo currículo, nos quatro primeiros semestres são oferecidos subsequentemente os Colóquios I, II, III e IV, e os Seminários Integrados de Atividades em Física e Química, no terceiro semestre. Também fazem parte dessa fase da formação três disciplinas oferecidas pela Faculdade de Educação: Problemas de Ensino de Física e Química (primeiro semestre); Escola e Cultura (segundo semestre); Psicologia e Educação (quarto semestre); e uma disciplina ofertada pelo Instituto de Geociências: Ciência, Tecnologia e Sociedade (primeiro semestre), cuja temática está diretamente relacionada com a formação de professores de ciências. As demais disciplinas cursadas nos quatro primeiros semestres, oferecidas pelos Institutos de Química, Física e Matemática, possuem um caráter mais geral, sendo as turmas constituídas por licenciandos e estudantes de outros cursos.

Considerando as possíveis trajetórias em termos curriculares e o contexto no qual os licenciandos se inserem, é importante trazer alguns elementos sobre quem participou da pesquisa. Os dois grupos ${ }^{1}$ são constituídos, em sua maioria, por jovens de ambos os sexos que concluíram recentemente o ensino médio em escolas públicas, os quais optaram pela licenciatura no momento da inscrição no vestibular. Em relação às trajetórias de cada licenciando, podemos dizer que muitos seguem o mesmo caminho no que se refere às disciplinas oferecidas pela Faculdade de Educação e Instituto de Geociências, havendo variações com as demais disciplinas de Química, Física e Matemática, já que há um número expressivo de reprovações nas mesmas.

É importante destacar também o fato de que as produções foram realizadas no momento o velho currículo ainda estava em vigência, sendo que parte das disciplinas oferecidas para o novo currículo era a mesma que compunha o antigo. Desse modo salientamos que, embora a maioria dos estudantes que participaram da pesquisa tivesse passado pelas disciplinas e atividades previstas no novo

1. Participaram da pesquisa dois grupos de estudantes da Licenciatura Integrada: denominaremos de G2 o grupo de estudantes que naquele momento cursava o segundo semestre e de G4 o grupo que cursava o quarto semestre. 
currículo, estava inserida num ambiente em que os dois modelos conviviam.

Mas o que dizem as produções dos estudantes? Partindo de uma mesma situação na qual foram instigados a produzir um texto sobre sua formação e atuação profissional, as produções nos revelam, tanto as concepções trazidas para o curso de licenciatura, quanto aquelas que estão se formando.

\section{O aluno, o licenciando e o professor. Dois momentos de uma formação}

Embora tratemos de dois grupos que estão sob o mesmo modelo curricular, as produções apresentam diferenças significativas entre os grupos do segundo (G2) e o do quarto semestre (G4) ${ }^{2}$. Encontramos nos textos marcas que revelam diferentes modos de ver e pensar o professor, o aluno e as práticas.

Iniciamos a leitura dos textos procurando elementos comuns considerados como relevantes pelos estudantes em suas experiências de formação. As primeiras leituras mostraram algumas convergências, já que os mesmos, em sua maioria, ao falarem da formação e da futura atuação, se remetiam a três focos: o professor, o aluno e a prática. De certo modo cada um procurou responder as seguintes questões: Que professor serei eu? Como me relacionarei com meus alunos? Como atuarei em sala de aula?

Escrever a partir de uma projeção, de um vir a ser, exigiu de nossos licenciandos um debruçar-se sobre o presente, naquilo que vivem na licenciatura e, ao mesmo tempo, um olhar sobre um passado não muito distante, voltando-se para suas experiências enquanto alunos do ensino fundamental e médio. Mas no que diz respeito à formação na Licenciatura, à medida que trafegamos das produções do G2 para o G4, encontramos elementos que, de algum modo, estão associados ou refletem os conteúdos das disciplinas já cursadas. Observamos a absorção e uso de determinados termos e conceitos, alguns até com certa frequência, que são comuns ao vocabulário pedagógico das disciplinas cursadas até então.

Sobre as diferenças que caracterizam mudanças nas concepções ao longo do curso, podemos tomar como exemplar a presença nos textos do G2 das referências à transmissão dos conhecimentos, como um elemento central na relação pedagógica, constituindo-se numa das preocupações primeiras para o

2. Por se tratar de duas turmas no início do curso, associado ao fato da pesquisa ter sido conduzida pelo coordenador do curso daquele momento, foi dada a opção aos estudantes de se manterem incógnitos em suas produções. Desse modo, identificamos apenas a turma a que pertence cada produção, e cada texto recebeu um código que permite distingui-lo dos demais. Os 19 textos do segundo semestre receberam a seguinte codificação, que vai de E1-G2 a E19-G2; já os 14 textos do quarto semestre: de E1-G4 a E14-G4. 
futuro professor. Encontramos o uso das expressões transmitir e/ou transmitir o conhecimento nos textos de: E1-G2; E2-G2; E4-G2; E12-G2; ou o uso de outras expressões denotando o mesmo sentido, tais como: passar conteúdo, por E3-G2; melhorar o meu modo de ensino, por E5-G2; aprimoramento do ensino por E7-G2; enfim, expressões e modos de dizer que revelam uma concepção da relação pedagógica, reduzida a um processo de comunicação, no qual o professor é o agente transmissor de conhecimentos e os alunos os receptores.

Já nos textos do G4 o uso de tais expressões não é comum, aparecendo com certa frequência referências à construção do conhecimento, na perspectiva de uma relação pedagógica que não está restrita a um caminho de mão única - do professor para o aluno -, mas que valoriza a interação. E1-G4 nos diz: irei estimular os alunos a participarem das aulas; enquanto que E12-G4, explicitamente se contrapõe a um determinado modelo: o papel do professor não apenas como transmissor do conhecimento, mas também como educador e formador; na perspectiva de uma relação pedagógica que toma como um dos seus princípios a interação professor-aluno.

Ao mesmo tempo em que em parte dos textos do G2 a transmissão do conhecimento é tomada como elemento central na relação pedagógica, e neste sentido definindo o papel do professor, nos deparamos também com uma concepção pragmática de formação, na qual a graduação é o momento em que os futuros professores são preparados para o exercício do magistério, o que nesse caso significa serem preparados para transmitirem conhecimentos. A graduação é o momento em que aprendem os conteúdos e as formas de transmiti-los, bem como o uso dos recursos disponíveis para esse fim, como está explícito no texto de E1-G2: não basta saber (obter conhecimento), é necessário saber transmitir, sendo assim preciso conhecer diversos métodos de dizer a mesma coisa. Nessa concepção de uma formação técnica encontramos falas como a de E7-G2, na qual o professor deve aplicar a tecnologia da informação no aprimoramento do ensino de ciências no país, já que a Licenciatura ensina o aprender para ensinar, o que é considerado uma habilidade fundamental para o professor. Podemos inferir que essas colocações expressam as expectativas que os estudantes trazem para o curso.

Nessa perspectiva o professor é concebido como centro do processo de ensino e aprendizagem, cujo resultado depende quase que exclusivamente de sua competência técnica e dedicação. Em seus textos os estudantes atribuem ao professor uma série de incumbências, E1-G2 comenta que a atuação do professor terá intuito de transmitir o maior número de conhecimento possivel, ao mesmo tempo em que deve cultivar a curiosidade dos alunos, já E6-G2 quer um professor que desafie os alunos a aprender e que os mesmos sintam prazer nisto. Outros, embora desejem um profissional diferenciado, mais próximo dos 
alunos, não excluem do professor a atribuição de controlar o processo. E11-G2 nos diz: serei um professor que está mais perto dos alunos, mais preocupado com o entendimento e nivelamento da sala, e não com o cumprimento do programa estabelecido.

Já os textos do G4 mostram um deslocamento do olhar para o aluno, suas preocupações não se prendem mais ao domínio de técnicas pelo professor, ou ao uso dos recursos disponíveis, voltando-se para a capacidade do professor de olhar e entender os seus alunos, de perceber as diferenças e respeitar o ritmo de aprendizagem de cada um. Ao falar da sua formação a estudante E2-G4 diz: pude passar a enxergar melhor o lado dos alunos, em relação a sua futura prática profissional diz que deseja: conhecer bem os meus alunos, conhecer sua realidade. No mesmo sentido E5-G4 diz que vai procurar o momento vivido também pelo aluno, assim como saber lidar com as diferenças. E8-G4 sintetiza esse novo olhar, se contrapondo ao modelo da transmissão e recepção, dizendo que deseja: olhar o aluno como ser humano, com sentimentos e emoções e não como receptores de conteúdo. Esse olhar para o outro, visto em sua dimensão psicológica e cultural, está em sintonia com os conteúdos e as dinâmicas presentes em diferentes disciplinas desenvolvidas nos quatro primeiros semestres do curso, especialmente aquelas que abordam as questões do ensino e da aprendizagem em seus aspectos psicológicos e culturais.

\section{Relevância aos aspectos social e político da educação}

Outro elemento que chama a atenção nos textos são as preocupações e reflexões que tomam a dimensão social e política da educação, especialmente no que se refere ao papel do professor e à formação que é dada aos alunos da educação básica. E3-G4 nos fala de suas intenções e como vê o papel do professor, dando um sentido político para essa atuação e desatrelando-a do que considera as exigências do mercado de trabalho: terei uma atuação no sentido de formar cidadãos críticos e não "profissionais dinâmicos", que é a necessidade deste modelo Toyotista. E12-G4 ao destacar os elementos da sua formação coloca que: a questão do ensino para a cidadania teve papel principal. Referências à formação do cidadão também estão presentes em outros textos, como do E6-G4, que fala em formar cidadãos pensantes e autocríticos.

Sobre essa questão é importante destacar que a expressão "formar o cidadão", definida como um dos papéis da educação básica, está presente nos textos e nos discursos dos especialistas, especialmente em trabalhos sobre a educação 
científica, a pelo menos duas décadas ${ }^{3}$.

E4-G4 usa do momento da produção do texto para criticar alguns aspectos da formação que vem recebendo, especialmente do que considera a falta de compromisso dos seus formadores com as questões da educação e seu sentido político: Falta de seriedade dos professores com estas disciplinas, muitos que estão lecionando estas aulas não acreditam que elas irão trazer elementos positivos para os educadores e a educação. Mas embora cobre um maior comprometimento dos seus formadores, vê a opção pelo magistério como um ato marcado pelas paixões individuais e por um certo voluntarismo: eu acredito que o amor pelo que se faz é algo que não se aprende nestas aulas (e nunca será) e muitos transmitem isto em suas aulas.

Assim como o tema "formação do cidadão" que faz parte da educação em ciências, outros também estão presentes, como é o caso do "cotidiano"4. Tanto nas produções do segundo como no do quarto semestre a ideia de um ensino que contemple as questões do cotidiano, ou mesmo que tome o cotidiano como um elemento norteador de uma proposta didática se faz presente nos textos. E9-G4 nos diz que irá tentar com que os alunos façam associações com o cotidiano, enquanto que E1-G4 quer ensinar os alunos entenderem o que é uma reação química e como elas estão presentes no dia-a-dia deles.

Além das questões que são características do ensino das Ciências, também estão presentes as preocupações de caráter mais geral, como o papel social da educação e os sentidos do trabalho docente, decorrentes das suas experiências de formação. E12-G4 ao falar das disciplinas que cursou e das possíveis influências em sua atuação profissional nos diz que tais disciplinas proporcionaram uma nova maneira de pensar sobre a educação e sobre a importância da mesma na sociedade.

Aparecem também destaques para a construção do olhar sobre o cotidiano escolar, visto como elemento fundamental para compreender a complexidade da realidade escolar e ter pistas de como enfrentar algumas situações. E12-G2, ao falar da formação que vem recebendo no curso de licenciatura, nos diz que

3. A questão da cidadania e da formação do cidadão se faz presente em trabalhos de especialistas na área de ensino de ciências. No ensino de química destacamos as produções de Wildson L. P. Santos. Conf. SANTOS, Wildson L. P.; SCHNETZLER, Roseli P. Função Social: O que significa ensino de química para formar o cidadão. Química Nova na Escola, n. 4, nov. 1996.

4. A partir da década de oitenta o tema do cotidiano terá uma presença significativa no ensino de química, inicialmente em trabalhos acadêmicos, teses e demais trabalhos, posteriormente será incorporado, inclusive por publicações didáticas de grande circulação. Sobre este tema destacamos as obras: LUTFI, Mansur. Cotidiano e educação em química: os aditivos em alimentos como proposta para o ensino de química no 2. ${ }^{\circ}$ grau. Ijuí-RS: Ed. UNIJUÍ, 1988. LUTFI, Mansur. Os Ferrados e os Cromados. Ijuí-RS: Ed. UNIJUÍ, 1992. LOPES, Alice Ribeiro Casimiro. Ensino de química e conhecimento cotidiano. São Paulo: Moderna, 1998. 
tem como fator diferenciador as abordagens e as discussões em sala de aulas sobre o cotidiano escolar ${ }^{5}$.

Mas a leitura dos textos mostra que as preocupações com o "como agir" não são expurgadas. Se num primeiro momento da formação essa dimensão é pensada a partir de um modelo abstrato e universal de aluno, com regras que se aplicam a todas as situações, ao incorporarem o discurso das diferenças, surgem novos questionamentos, em alguns casos, expressos como uma crítica ao currículo vigente, trazendo à tona a pergunta: como agir diante das diferenças?

\section{Textos de alunos do curso de Licenciatura em Química da UNESP}

Conforme explicado anteriormente, os licenciandos dessa Universidade passaram por um processo formativo que privilegia a carga horária das disciplinas de caráter específico em detrimento às pedagógicas. No início do curso, disciplinas como História e Filosofia da Ciência, Fundamentos da Educação, Estrutura e Funcionamento do Ensino Médio, Didática e Psicologia da Educação contribuíram para a aprendizagem docente. Ao final, outras duas disciplinas pedagógicas, mas com ênfase no ensino de Química, completam o rol: Prática de Ensino I (teoria) e Prática de Ensino e Estágio Supervisionado.

Percebemos em seus depoimentos algumas marcas deixadas pelas disciplinas específicas de formação de professores, assim como sinais de possíveis mudanças em suas concepções durante o curso de Licenciatura, os quais serão comentados a seguir.

Analisando as vozes do licenciandos podemos identificar dois grupos de respostas, isto é, as que valorizam, dentre outros aspectos, a importância da apropriação de conhecimentos, saberes e fazeres (aproximadamente metade da turma), e as que demonstram certa inquietação quanto à contribuição das disciplinas pedagógicas para a formação de professores.

\section{Apropriação de conhecimentos, saberes e fazeres}

As universidades cujos cursos de formação de professores possuem influência da pesquisa em Educação em Ciências têm estabelecido consensualmente a importância da adoção de inovações pedagógicas construtivistas para o ensino

5. As referências à vida escolar em seus múltiplos aspectos fazem parte de disciplinas do novo currículo, como Escola e Cultura, cujos alunos da Licenciatura Integrada cursam no segundo semestre. 
médio (Física e Química) trabalhadas em algumas disciplinas que procuram integrar os conhecimentos sobre o conteúdo aos saberes provenientes da pesquisa em Educação ou da Educação em Ciências. Temas integradores como concepções alternativas, aprendizagem por investigação, resolução de situações-problema, uso da História e da Filosofia da Ciência, discussão sobre visão de ciência e linguagem em sala de aula, já fazem parte, hoje, do cotidiano de muitos cursos de formação inicial e continuada espalhados por todo o país (QUEIROZ; BARBOSA-LIMA, 2007). Nesse sentido, vários licenciandos salientaram a importância de conhecimentos teóricos diversos debatidos em sala de aula assim como de ferramentas para uma melhor atuação, conforme depoimentos:

Duas disciplinas permanecem bastante vivas em minha memória. A $1 .^{\mathrm{a}}$ mudou minha maneira de ver o processo ensino-aprendizagem, passando a olhar o aluno e não o conteúdo como elemento principal desse processo. A outra foi aquela que mais me aproximou da vida de professor me colocando diante de diversas situações vivenciadas para esse profissional. Pude conhecer quatro diferentes orientações pedagógicas que me auxiliaram na utilização de diferentes metodologias e recursos para preparar e ministrar uma aula mais proveitosa e efetiva.

Dentre as disciplinas pedagógicas [...] aprendi temas que para mim foram muito importantes não só pelo lado pedagógico, mas também pelo lado cultural. Começamos a pensar em uma aula como professores e a nos preocupar em como montar uma boa aula utilizando diferentes estratégias de ensino. As críticas negativas e positivas dos alunos e da professora ajudaram muito a como melhorar como profissional.

Notamos também que os licenciandos apresentam uma preocupação com a mudança substancial de foco de uma pedagogia de ensino para uma pedagogia da aprendizagem, ou seja, a mudança dos processos de ensinar e aprender de um modelo "professor centrado", para um modelo que pode ser denominado "aluno centrado" (STEDILE, 2008).

Passei a ver com olhos mais "humanos" para os alunos, levando em conta que estes possuem virtudes e falas, assim como eu, e que cada um deles tem sua história de vida desvinculada da sala de aula, o que me leva à necessidade de uma "avaliação individual" de cada aluno no que diz respeito à velocidade e forma de aprendizagem. 
Entendemos, assim como Isaía (2008), que a aprendizagem docente compreende as diversificadas atividades regidas pelo mundo de vida e da profissão e alicerçadas não só em conhecimentos, saberes e fazeres, mas também em relações interpessoais e vivências de cunho afetivo, valorativo e ético. E, sobre esse último aspecto trazemos outro depoimento:

Nunca perdi o foco de que sempre me interessei em trabalhar com pessoas e não única e simplesmente com equipamentos e vidrarias. Durante a faculdade as matérias didáticas ou pedagógicas contribuíram consideravelmente sobre uma formação mais humanística da minha pessoa, tanto no relacionamento com os alunos, direção e outros professores quanto no que diz respeito, a saber, lidar corretamente com as situações conflitantes que possam surgir.

Considerando as vozes desses licenciandos podemos extrair marcas deixadas pelo curso como a possibilidade de abertura e receptividade a aceitar novas formas de se constituir, tanto em termos de conhecimentos específicos quanto pedagógicos e profissionais.

Por outro lado, sabemos que os processos de aprender a ensinar e de aprender a ser professor são lentos, pois se iniciam antes do espaço formativo dos cursos de licenciatura e se prolongam por toda a vida profissional. A escola e outros espaços de conhecimento são contextos importantes nessa formação assim como aqueles que têm como fonte a experiência pessoal e profissional que são objetos de aprendizagens constantes (MIZUKAMI, 2008).

\section{Inquietação}

Outros licenciandos apresentam uma visão mais crítica sobre as marcas deixadas pelas disciplinas de formação de professores:

Os próprios professores tinham atitudes que muitas vezes eram criticadas por eles.

Como poderíamos falar em ensino e aprendizagem em química se nossos professores não possuíam formação em química? 
Algumas disciplinas pedagógicas tratam da escola ideal, no país ideal, com aluno ideal e infra-estrutura ideal.

Faltou um pouco de participação dos alunos como sujeitos ativos e não como meros espectadores.

As vozes desses licenciandos, em contrapartida ao primeiro grupo, chamam a atenção para um aspecto muito importante no processo ensino-aprendizagem: a postura do professor formador. Este ao formar também se forma, compartilha; o que implica trocas e representações. Segundo Isaía (2008, p. 224):

o professor, ao ensinar, aprende com seus alunos. Para tanto precisa estar voltado para a possibilidade da incerteza e da dúvida, denotando espírito aberto para o novo e humildade para não adotar uma posição autoritária, ao mesmo tempo em que está ciente de sua responsabilidade em conduzir o processo formativo dos alunos, tendo como meta o desenvolvimento dos mesmos, como pessoas e profissionais.

Outro objeto de estudo desse trabalho diz respeito às possíveis mudanças na concepção de ensino ocorridas ao longo do curso e que terão alguma influência na atuação profissional. Com esse fim, identificamos deslocamentos que serão apresentados a seguir.

\section{Abordagem do conteúdo: uso de diferentes estratégias, ensino com o lúdico e desmistificação da Química}

A importância da abordagem do conteúdo foi citada na maioria das vozes dos licenciandos. Para eles, conhecer o conteúdo não é suficiente para quem quer ensinar; é preciso muito mais do que isso.

Ao ser professora quero aplicar abordagem como, por exemplo, CTS, experimentação, inovação tecnológica, História da Ciência para possibilitar o melhor aprendizado de cada aluno.

A minha maior meta (e diferencial, acredito) será fazer o aluno aprender se divertindo, porém sem nunca perder o foco. 
Creio que minha atuação será, com a prática, bem divertida e os alunos deverão gostar. Não posso dizer que sou convencional (lousa, giz) quando dou aula, mas também não posso dizer que sou totalmente com um jeito peculiar. Um pouco de cada teoria de ensino e sempre procuro desmistificar a química com os contextos que nos foram apresentados.

Apesar do forte apelo à questão conteúdo versus forma no ensino, as vozes desses licenciandos deixam implícito outro aspecto importante sobre a não consciência de que possuem uma formação docente anterior, adquirida ao longo de muitos anos em que, como alunos, estiveram em contato com seus professores e que essas experiências têm um peso considerável e porque não dizer determinante na futura atuação profissional. A utilização de estratégias que supõe a construção de conhecimentos de todos em conjunto visando uma aprendizagem mais efetiva, conforme mencionado anteriormente por um dos licenciandos requer considerar as ideias, visão de mundo, destrezas e atitudes que os alunos possuem. Essa visão de ensino, se por um lado parece mais adequada, por outro, pode dar a impressão de uma assimetria entre o discurso propositivo e a experiência concreta.

\section{Interação professor-aluno: concreta, focada no aluno e baseada em valores}

A relação professor-aluno verticalizada que tem num dos polos o professor como detentor do conhecimento foi bastante criticada e explicitada nas vozes dos licenciandos:

Acredito que no caso eu tenha sido contratado pela escola, primeiramente vou me diferenciar dos meus professores em alguns aspectos como, por exemplo, na proximidade do aluno-professor desmistificando a barreira de hierarquia criando um ambiente agradável. Além disso, acredito que o aluno será o centro da aula e não o conteúdo, pois somente com a interação e reflexão o aluno vai poder aprender. E, por fim, formar um aluno que possa ser cidadão capaz de relacionar-se com a sociedade tendo valores como moral, respeito e ética.

Para ser uma boa professora, preciso conhecer cada aluno para fazer o meu objetivo ser alcançado: que ele aprenda.

Focar sempre no aluno como ser que interage e que deve participar de forma efetiva do processo de ensino-aprendizagem. 
Analisando essas vozes parece coerente a ideia de que caberá a um professor inovador ou não tradicionalista uma relação mais amigável com seus alunos, conforme mencionado anteriormente por um dos licenciandos. Sabemos que, dessa forma, caberá a ele criar situações propiciando condições, nas quais possam estabelecer reciprocidade intelectual e cooperação.

\section{Considerações finais}

Embora os cursos de formação inicial certifiquem o professor para o exercício da docência, tais cursos devem ser entendidos dentro de seus limites formativos. Devemos levar em consideração que temos alunos diferentes com trajetórias pessoais e culturais diversas e também que o processo formativo supõe: o conhecimento de diferentes teorias e propostas educacionais que possibilite a compreensão mais aprofundada e mais abrangente do fenômeno educacional e do processo de ensino e aprendizagem; a capacidade de descrever - objetiva e subjetivamente - as práticas pedagógicas em seus múltiplos determinantes, contextos e variáveis; a disposição para realizar constantemente o movimento teoria-prática-teoria e a capacidade de trabalhar com certezas, incertezas, dilemas, problemas e de reconhecer que a investigação tanto surge de certezas quanto gera questões que desafiam o sistema, envolvendo aprendizagens e desaprendizagens (MIZUKAMI, 2008).

Ao analisarmos as vozes dos licenciandos nos defrontamos com a necessidade de reconhecer os indícios dos processos de significação inscritos sem nos preocuparmos em extrair um conteúdo por trás delas. Nas produções dos estudantes, principalmente quando falam de suas experiências de formação anteriores, e projetam um futuro no qual se veem no exercício profissional, faz-se presente também o desejo de não repetir determinados modos, especialmente aqueles que consideram como barreiras ou suscitam a animosidade dos alunos do ensino médio para com as ciências, em especial a Química e a Física, atribuindo ao futuro professor o papel de assumir posturas em sala que permitam superar esta situação.

No que se refere às concepções dos licenciandos e as possíveis mudanças que ocorrem ao longo do curso, especialmente no contato com disciplinas pedagógicas, as análises das concepções expressas em diferentes momentos da formação, assim como das marcas deixadas por tais disciplinas, que estas possuem um papel fundamental na formação, especialmente na construção de um olhar sobre a atividade docente, voltando-se para os aspectos sociais, humanos 
e culturais que envolvem tal prática, permitindo pensar o professor como agente de um processo social em transformação.

Finalmente, podemos dizer que as manifestações dos estudantes expressam um processo de formação que é também um processo pelo qual adentram ao universo do ser professor, sendo a incorporação dos modos discursivos que permeiam o exercício deste ofício parte do processo de constituição dos sujeitos em suas posições.

\section{REFERÊNCIAS}

ALMEIDA, M. J. P. M. Discursos da ciência e da escola: ideologia e leituras possíveis. Campinas: Mercado de Letras, 2004.

FOUCAULT, M. A arqueologia do saber. 2. ed. Rio de Janeiro: Forense Universitária, 1986.

ISAIA, S. M. A. Aprendizagem docente: sua compreensão a partir das narrativas de professores. In: ENCONTRO NACIONAL DE DIDÁTICA E PRÁTICA DE ENSINO, 14, 2008, Porto Alegre. Anais... Porto Alegre, 2008. CD-ROM.

LOPES, A. R. C. Ensino de química e conhecimento cotidiano. São Paulo: Moderna, 1998.

LUTFI, M. Cotidiano e educação em química: os aditivos em alimentos como proposta para o ensino de química no 2. ${ }^{\circ}$ grau. Ijuí: Ed. UNIJUÍ, 1988.

. Os Ferrados e os Cromados. Ijuí: Ed. UNIJUÍ, 1998.

MIZUKAMI, M. G. N. Formação continuada e complexidade da docência: o lugar da universidade. In: ENCONTRO NACIONAL DE DIDÁTICA E PRÁTICA DE ENSINO, 14, 2008, Porto Alegre. Anais... Porto Alegre, 2008. CD-ROM.

NASCIMENTO, T. G.; SOUZA, S. C. Expectativas, conflitos e reflexões nos discursos de licenciandos em formação inicial. In: ENCONTRO NACIONAL DE DIDÁTICA E PRÁTICA DE ENSINO, 14, 2008, Porto Alegre. Anais... Porto Alegre, 2008. CDROM.

ORLANDI, E. P. A linguagem e o seu funcionamento: as formas do discurso. CampinasSP: Pontes, 1988. 
. A linguagem e o seu funcionamento: as formas do discurso. 4. ed. São Paulo: Pontes, 1996.

2005.

. Análise de discurso: princípios e procedimentos. 6. ed. Campinas: Pontes, . Discurso e leitura. 2. ed. São Paulo: Cortez, 1993.

PÊCHEUX, M. Semântica e discurso: uma crítica à afirmação do óbvio. 2. ed. Campinas: Editora da Unicamp, 1995.

QUEIROZ, G. R. P. C.; BARBOSA-LIMA, M. C. A. Conhecimento científico, seu ensino e aprendizagem: atualidade do construtivismo. Ciência \& Educação, v. 13, n. 3, p. 273-291, 2007.

SANTOS, W. L. P.; SCHNETZLER, R. P. Função Social: O que significa ensino de química para formar o cidadão. Química Nova na Escola, n. 4, nov. 1996.

STEDILE, N. L. R. Processos de ensinar e aprender: aprendizagem da docência na educação superior. In: ENCONTRO NACIONAL DE DIDÁTICA E PRÁTICA DE ENSINO, 14, 2008, Porto Alegre. Anais... Porto Alegre, 2008. CD-ROM.

TARDIF, M. Saberes docentes e formação profissional. 4. ed. Petrópolis: Vozes, 2004. 